\title{
Um olhar sobre condições de vida: mortalidade de crianças e adolescentes residentes em Manguinhos, Rio de Janeiro, Brasil
}

\author{
A perspective on living conditions: \\ child and adolescent mortality in Manguinhos, \\ Rio de Janeiro, Brazil
}

Marcelo Rasga Moreira 1

Otavio Cruz Neto ${ }^{\dagger}$

Luiz Fernando Mazzei Sucena 1

1 Departamento de Ciências Sociais, Escola Nacional de Saúde Pública,

Fundação Oswaldo Cruz. Av. Leopoldo Bulhões 1480, Rio de Janeiro, $R J$ 21041-210, Brasil rasga@ensp.fiocruz.br lfmazzei@uol.com.br † Falecido.

\begin{abstract}
Using data from the Mortality Information System, this paper investigates the deaths of children and adolescents in the Manguinhos neighborhood from 1996 to 2000, to determine the main characteristics and associate key mortality aspects with local living conditions. An outlying working-class or "suburban" neighborhood of the city of Rio de Janeiro where the main campus of the Oswaldo Cruz Foundation is located, Manguinhos consists of 12 "communities" characterized by poverty, social exclusion, drug traffic, and structural violence. In light of these factors and the cultural, social, and economic potential of the Manguinhos population, the authors begin with the theoreticall practical premise that living conditions played a major role in the deaths of these young citizens. The study of these fatal events may therefore lead to the elucidation of issues and problems that must be included on the agendas and in forums involving both health promotion projects and the Municipal, State, and Federal governments so that they can be appropriately addressed in the scope of public policies.
\end{abstract}

Key words Mortality; Living Conditions; Child Health; Adolescence

Resumo Neste artigo são investigados, com base nos dados do Sistema de Informação de Mortalidade (SIM), os óbitos de crianças e adolescentes residentes em Manguinhos, no período 1996 a 2000, tendo como objetivo apurar suas principais características e relacionar determinados aspectos da mortalidade às condições locais de vida. Bairro da zona suburbana no Município do Rio de Janeiro, onde está instalado o campus principal da Fundação Oswaldo Cruz, Manguinhos é formado por 12 "comunidades", nas quais pontificam a pobreza, a exclusão social, o tráfico de drogas e a violência estrutural. Conscientes de tais situações e do potencial cultural, social e econômico da população de Manguinhos, os autores partem da premissa teórico-prática de que as condições de vida influenciaram bastante na morte daqueles cidadãos. Assim, o estudo desses eventos fatais possibilita a elucidação de questões e problemas que devem ser incluídos nas agendas e fóruns, tanto dos projetos de promoção da saúde, quanto do poder público municipal, estadual e federal, a fim de serem devidamente enfrentados no âmbito das políticas públicas. Palavras-chave Mortalidade; Condições de Vida; Saúde da Criança; Adolescência 


\section{Introdução}

O bairro de Manguinhos localiza-se, de acordo com os referenciais geopolíticos e gerenciais adotados pela Prefeitura da Cidade do Rio de Janeiro (PCRJ), na zona suburbana da Leopoldina, integrando, juntamente com Ramos, Bonsucesso e Olaria, a X Região Administrativa (RA) do Município e, por conseguinte, a Área de Planejamento (AP) 3.1 da Secretaria Municipal de Saúde (SMS-RJ), que congrega também as RAs da Penha (XI), Ilha do Governador (XX), Complexo do Alemão (XXIX) e Maré (XXX).

Possuindo, em 2000, uma população de 31.037 habitantes (SMS, 2001), dos quais cerca de $40,0 \%$ eram crianças e adolescentes, Manguinhos tem como principal característica sóciopolítica o fato de ser composto por 12 comunidades e favelas, nas quais as condições de vida são bastante problemáticas, chegando, nas mais pobres, a apresentar um panorama de extrema precariedade.

De acordo com o Índice de Qualidade de Vida elaborado pela Universidade Federal Fluminense (IQV/UFF), dos 153 bairros do Município do Rio de Janeiro, Manguinhos é o 139o colocado. Levando em conta uma cesta de indicadores, dentre os quais sobressaem os que mensuram a abrangência da rede geral de água e esgoto; a coleta de lixo; a renda mensal e o percentual de chefes de domicílio abaixo da linha da pobreza; a taxa de alfabetização e os anos de estudos, bem como as relações leitos/habitantes e médicos/habitantes (Almeida, 1997), esse índice aponta uma importante parcela dos problemas sociais enfrentados pela população de Manguinhos.

A esses problemas integram-se os levantados por Moreira et al. (2001), que, ao desenvolverem o "Estudo sobre as Condições de Vida e Atendimento a Crianças e Adolescentes do Município do Rio de Janeiro - X RA/Ramos”, identificam e denunciam a inexistência de espaços adequados para lazer; a rarefação de instituições de atendimento a crianças e adolescentes; a poluição atmosférica; as "casas" de compensado e madeira erguidas na beira dos rios; a baixa auto-estima; o alcoolismo e as demais dependências químicas; os elevados níveis de desemprego e subemprego e a forte presença do tráfico de drogas.

O caráter sui generis desse bairro é ainda mais ressaltado pela presença centenária da Fundação Oswaldo Cruz (FIOCRUZ), cujo campus principal, em especial na área da Escola Nacional de Saúde Pública, é separado de algumas das comunidades de Manguinhos por um rio insalubre, construindo uma territorialidade que torna extremamente pronunciada as discrepâncias e problemas sociais.

Enfrentando suas próprias dificuldades sócio-políticas e premidos pelos limites de recursos financeiros e humanos, os pesquisadores, técnicos e demais profissionais dessa instituição têm se dedicado, historicamente, a apoiar a população de Manguinhos, desenvolvendo importantes projetos voltados para a melhoria das condições de vida de seus vizinhos. Sem estabelecer escalas de importância ou representar demérito para outras atividades tão qualificadas quanto, destacar-se-ia o Projeto Universidade Aberta; o Centro de Saúde Escola Germano Sinval Farias (CSEGSF), com seus programas, serviços e o apoio ao Programa Saúde da Família (PSF) da PCRJ, e o Projeto de Desenvolvimento Local Integrado e Sustentável (DLISManguinhos).

Voltados, sobretudo, para a geração de emprego e renda, para a promoção da saúde e para o incentivo à mobilização e à organização popular em torno de seus direitos e condições de vida, projetos de intervenção social como esses preocupam-se diretamente com um dos principais desafios da saúde pública contemporânea: desenvolver pesquisas, trabalhos e atividades que propiciem retorno social a curto e médio prazo para a população local e, ao mesmo tempo, reconheçam as possibilidades e limites desta atuação, preparando os cidadãos para que assumam seu papel de protagonistas do processo histórico.

Categoria extremamente complexa, guarda-chuva de vários estudos, mas ainda não suficientemente debatida e refinada, as condições de vida são aqui compreendidas, em sentido lato, como a síntese das relações (econômicas, sociais, políticas, culturais, afetivas...) travadas pelos indivíduos que compõem um determinado grupo ou classe social, visando a satisfazer suas necessidades e expectativas.

Dialeticamente, as condições de vida são resultantes da ação humana, que por elas é diretamente influenciada. Delineiam um leque de características conjunturais e estruturais que, ao ser analisado em perspectiva e comparativamente ao de outros grupos e classes sociais, expressa os diferentes níveis de bem-estar existentes em uma determinada etapa do processo histórico, definindo as múltiplas qualidades sociais (e, portanto, de vida) que podem, ou não, ser usufruídas pelos seres humanos.

Tamanha complexidade exige daqueles que pesquisam as condições de vida uma postura que, atendendo a pressupostos didáticos e metodológicos, direcione-os a produzir trabalhos nos quais fiquem nítidos o 'olhar' que preten- 
dem empregar, definindo, pelo menos, a população-alvo, seus objetivos, a forma como os realizou, os resultados obtidos e os comentários sobre estes.

Em face desses aspectos, o segmento formado por crianças e adolescentes, devido à sua importância sócio-política, às suas condições especiais de desenvolvimento biopsicosocial e às responsabilidades atribuídas pelo Estatuto da Criança e do Adolescente (ECA) e pela Constituição Federal ao poder público em seus diferentes níveis administrativos e de poder, sobretudo no que se refere à obrigatoriedade de promover e garantir seus direitos, constitui-se em população-alvo privilegiada.

Nesse contexto, o presente artigo pretende contribuir para a compreensão e a melhoria das condições de vida das crianças e adolescentes residentes em Manguinhos, investigando justamente sua mais extrema negação: os óbitos ocorridos neste segmento durante o período 1996 a 2000. Sua premissa teórico-prática baseia-se no fato de que a conjunção diária entre a ausência de perspectivas de futuro, a pobreza, a exclusão social, a delinqüência e a violência estrutural influenciaram de tal maneira a morte daqueles cidadãos, que o estudo destes eventos fatais tem a possibilidade de pontificar questões e problemas que devem ser incluídos nas agendas e fóruns, dos projetos tanto de DLIS e promoção da saúde, quanto do poder púbico municipal, estadual e federal, a fim de serem superados.

\section{Considerações metodológicas}

Os dados de mortalidade apresentados neste trabalho referem-se ao período 1996 a 2000 e foram coletados no Sistema de Informação de Mortalidade (SIM), cujos bancos de dados foram gentilmente cedidos pela Coordenação de Epidemiologia da SMS da PCRJ, que também repassou as informações referentes às populações e ao número de nascidos vivos. Ressaltese que, tanto para os bairros, quanto para as APs e Município, foram selecionados somente os óbitos ocorridos em residentes.

O referencial etário adotado foi o do ECA, Lei no 8069 de 13 de julho de 1990 (Brasil, 1990), que, em seu artigo 2o, estabelece que criança é a pessoa que possui de 0 a 12 anos incompletos e adolescente, a que possui entre 12 e 18 anos de idade.

A opção por tais parâmetros explica-se pela proposta de trabalhar-se em consonância com uma legislação que marca, na vida política brasileira, uma incisiva mudança de rumos. Nesse processo, a participação da sociedade civil organizada foi fundamental, criando as condições sócio-políticas necessárias para a promulgação de uma lei que concebe crianças e adolescentes como cidadãos de direitos, e põe termo ao Código de Menores, criado em 1979, durante a ditadura militar e sob os auspícios da Lei de Segurança Nacional.

Encampando-se essa proposta, torna-se nítida a dificuldade de trabalhar-se exclusivamente com as faixas etárias tradicionalmente utilizadas por órgãos oficiais, como o IBGE, e por estudos de caráter epidemiológico (“< 1 ano", "1 a 4", “5 a 9", “10 a 14" e “15 a 19”), o que não significa sua exclusão. Elas também foram contempladas, mas somente quando se enfocou, direta ou comparativamente, o bairro de Manguinhos. Nesses casos, houve apenas uma exceção: a faixa "15 a 19" foi transformada para “15 a 18”, uma vez que, para o ECA, a pessoa com 19 anos é um adulto.

Analisar os dados de mortalidade de um bairro de uma metrópole como o Rio de Janeiro constitui-se em tarefa complexa, demandando, antes de tudo, uma demarcação de limites e parâmetros. Neste trabalho, optou-se por um processo que visa a estabelecer um movimento que parte de uma escala macro - o município -, perpassa uma escala intermediária a área de planejamento - e enfatiza, por meio de interações comparativas, a escala micro, ou seja, o bairro.

Assim, os dados de Manguinhos, sempre que possível, foram situados no universo do Município do Rio de Janeiro e comparados com os de outros bairros, em especial Bonsucesso, Ramos e Olaria, que, junto com o primeiro, compõem a X RA. Adotando-se essa dinâmica, trabalhou-se a mortalidade proporcional por faixas etárias, a taxa de mortalidade infantil, a taxa de mortalidade neonatal, a taxa de mortalidade pós-neonatal, a taxa de mortalidade materna e a mortalidade por causas.

Concluindo o artigo, os principais aspectos da mortalidade infantil e da mortalidade de adolescentes de Manguinhos foram selecionados e relacionados a determinadas condições de vida das crianças e adolescentes residentes no bairro. Essa opção baseou-se em critérios práticos, pois os dados supracitados foram os que apresentaram as melhores condições de trabalho e análise, e, sobretudo, em critérios teóricos, uma vez que, conforme atestam Oliveira \& Mendes (1995:291): “De uma forma bem mais intensa de que a mortalidade adulta, os óbitos infantis estão sujeitos a várias condicionantes que atuam a partir da vida social... essa é uma mortalidade específica, fortemente in- 
fluenciada pelos agentes externos que estão localizadas na sociedade, seja na existência ou não de serviços de saúde, saneamento e higiene, seja nas relações familiares e sociais que organizam a existência concreta das pessoas (moradia, trabalho, renda, nível de informação, proteção social, etc.)", e, de acordo com Minayo (1990:36): "Embora no campo a violência das relações de poder, de propriedade e de sobrevivência esteja ceifando muitas vidas de crianças e jovens, é nas cidades, particularmente nas grandes metrópoles, que a morbi-mortalidade por causas externas se constitui no problema no 1 de Saúde Pública para adolescência".

As informações sobre as condições de vida da população de Manguinhos foram levantadas por meio de fontes secundárias e, principalmente, de fontes primárias, utilizando-se entrevistas semi-estruturadas realizadas pelos autores do artigo com nove profissionais que trabalham no PSF de Manguinhos.

Importante destacar que a escolha do PSF deve-se ao fato de sua equipe ter, dentre os objetivos de trabalho, a incumbência de reduzir taxas de mortalidade - sobretudo infantil - por meio da atuação nas comunidades atendidas, o que permite às profissionais travar um contato direto e diário com as condições de vida dos residentes.

Em "Termo de Consentimento Livre e Esclarecido", assinado em duas vias (ficando uma com as entrevistadas e outra com os pesquisadores), as profissionais do PSF-Manguinhos expressaram a concordância com a utilização de seus depoimentos em trabalhos de caráter exclusivamente científico (livros, artigos para publicação em periódicos e relatórios de pesquisa) elaborados somente pelos autores deste artigo.

Propõe-se, assim, uma permanente interação entre as dimensões quantitativas e qualitativas da pesquisa social, afirmando-se uma práxis científica que, não estando isenta de problemas e críticas, recobre-se de um potencial metodológico capaz de revelar e compreender importantes questões, contribuindo efetivamente para a melhoria das condições de vida da população com a qual se trabalha.

\section{Mortalidade de crianças e adolescentes residentes em Manguinhos}

No Município do Rio de Janeiro morreram, de 1996 a 2000, 306.849 pessoas, das quais 16.236 (5,3\%) eram crianças e 5.073 eram adolescentes $(1,6 \%)$. Ano a ano, o número absoluto de mortes tem decaído, sobretudo no que se refere aos adolescentes, que, em 1996, contavam
1.074 e, em 2000, foram 938, registrando queda de $12,7 \%$.

Em termos proporcionais, constatam-se, em especial no que concerne aos óbitos em adolescentes, índices estáveis, que permanecem em torno do patamar de 1,5\%. Esta tendência também está presente na mortalidade em crianças, com exceção para o ano 2000, quando, pela primeira vez nos cinco anos estudados, a proporção de óbitos ficou abaixo de 5,0\%.

Atendo-se à distribuição pelo território carioca do número de mortes ocorridas nos anos de 1996 a 2000, e levando-se em conta as cinco grandes áreas de planejamento (APs) da SMS / PCRJ, que congregam, de acordo com características geográficas, econômicas e sociais, as 32 Regiões Administrativas do Município, verifica-se que, dos 253.298 óbitos cujos registros indicam o bairro de residência $(82,5 \%$ do total de Registros de Óbitos), a AP 3 - Zona Suburbana é a que apresenta, tanto para a população em geral $(42,0 \%)$, quanto para crianças $(41,0 \%)$ e adolescentes $(44,0 \%)$, a maior proporção de óbitos.

Em seguida, surge a AP5 - Zona Oeste (área periférica), que nos três índices apresentados possui a segunda maior proporção de óbitos. Entretanto, enquanto esta é de $23,0 \%$ para o total de mortes, sobe para $29,0 \%$, nos adolescentes, e para $31,0 \%$, nas crianças. Em situação oposta, desponta a AP2 - Zonas Sul e Norte, que, embora registre a terceira maior proporção de óbitos em geral (20,0\%), apresenta considerável redução no que tange às mortes de crianças $(10,0 \%)$ e às de adolescentes $(10,0 \%)$.

Apesar de possuir um índice geral de óbitos (9,0\%) consideravelmente inferior ao da AP2, a AP4 - Jacarepaguá e Barra ultrapassa-a no tocante à mortalidade de crianças $(11,0 \%)$ e muito se aproxima na mortalidade de adolescentes $(9,0 \%)$. Por sua vez, a AP1 - Centro é a que apresenta os menores índices em todas as situações apresentadas: $6,0 \%$ para o total de óbitos; $7,0 \%$ para os óbitos em crianças e 8,0\% para os óbitos em adolescentes.

Focalizando-se a distribuição dos óbitos pelos bairros, constata-se que, em todos os anos, Campo Grande e Tijuca aparecem como os que apresentam o maior número absoluto de mortos, respectivamente, 15.081 (4,9\% do total) e 10.872 (3,1\%). Logo após, surgem Copacabana (9.622 óbitos) e Bangu (9.572 óbitos), que, no período estudado, alternam-se entre o terceiro e o quarto lugar. Destaque-se que, nesse período, os dez bairros com maior número de óbitos do município mantêm-se os mesmos e, no máximo, modificam sua posição em um determinado ano. Além dos quatro já citados, são eles (por ordem decrescente, de acordo com o número de 
óbitos ocorridos no ano 2000): Realengo, Santa Cruz, Bonsucesso, Irajá, Taquara e Penha.

Esse panorama modifica-se ao enfatizar-se o número absoluto de óbitos na faixa etária de 0 a 18 anos. Apesar de Campo Grande manter-se como o primeiro em todo o período (1.203 óbitos, o que equivale a 5,6\% dos óbitos de crianças e adolescentes), a Tijuca aparece em oitavo, em 1997, e em nono, em 1998, para, a partir daí, não mais figurar entre os dez bairros de maior ocorrência de morte de crianças e adolescentes. Essa situação acontece de forma ainda mais enfática em Copacabana, que, em nenhum ano, aparece nesta lista. Nesse contexto, Santa Cruz e Bangu fixam-se como segundo e terceiro bairros onde aconteceu o maior número de mortes nesta faixa etária. Dentre os demais, há uma certa alternância, sendo Bonsucesso e Realengo os únicos que aparecem em todos os anos.

Focalize-se, então, Manguinhos e sua colocação na lista do total de óbitos por bairros do Rio de Janeiro: de 1996 a 1999, ele oscila entre a 90 a e a 102a posição, e, em 2000, apresenta uma significativa subida, atingindo a 76a posição. Focando-se a faixa etária de 0 a 18 anos, essas colocações modificam-se bastante: no período 1996 a 1999, Manguinhos oscila entre

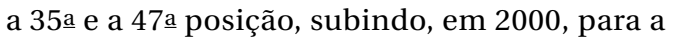
23a posição.

De 1996 a 2000, ocorreram 830 óbitos de residentes em Manguinhos (150, em 1996; 159, em 1997; 162, em 1998; 166, em 1999; e 193, em 2000), dos quais 84 (10,1\%) em crianças (15, em 1996 e 1997; 17, em 1998; 18, em 1999; e 19, em 2000) e $34(4,1 \%)$ em adolescentes (seis, em 1996 e 1997; sete, em 1998; quatro, em 1999; e 11, em 2000). Esses dados demonstram que, ao contrário do município, a tendência dos óbitos em Manguinhos é de crescimento: $28,9 \%$ para a mortalidade geral e $26,6 \%$ para a mortalidade de crianças.

Atendo-se à mortalidade proporcional de crianças e de adolescentes residentes em Manguinhos, percebe-se que ambas situam-se em patamares mais elevados que as do Município do Rio de Janeiro. A primeira apresenta um movimento oscilatório, cujo menor percentual foi de $9,4 \%$ (1997) e o maior de $10,8 \%$ (1999), encerrando o período em queda, com 9,8\%. A segunda, que também alterna queda e ascensão, atinge, em 2000, o índice de 5,7\%, o maior de todos os anos, o que indica que o crescimento do número de óbitos em Manguinhos, no período 1999-2000, foi influenciado pelas mortes de adolescentes.

Analisando-se os óbitos de crianças e adolescentes residentes em Manguinhos (Figura 1), constata-se que a faixa etária que registra o maior numero absoluto de mortes é a de menores de um ano, que, de 1996 a 2000, totalizava 63 óbitos, o que representava $57,4 \%$ do total. Logo após, surge a faixa de 15 a 18 anos, com 27 óbitos (23,0\%). Entretanto, no ano 2000, esta

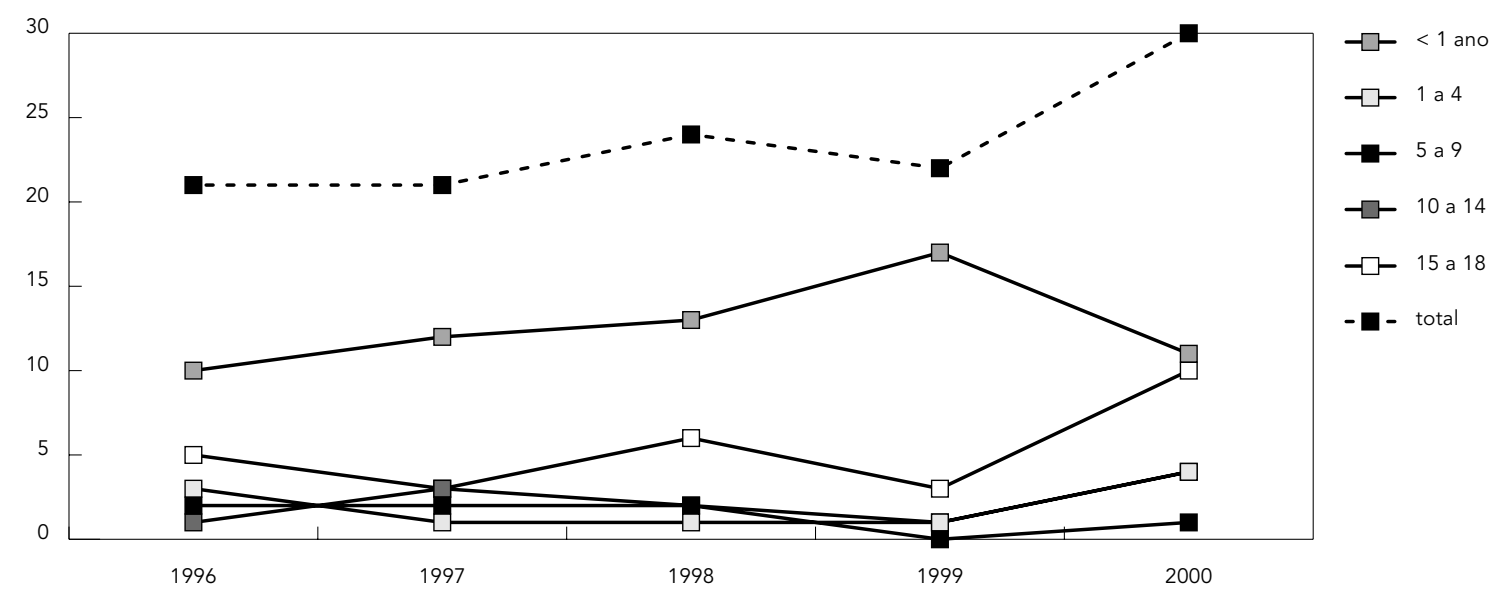


faixa apresenta incremento, atingindo dez óbitos, enquanto a de menores de um ano registra decréscimo, o que reduz a diferença entre ambas para apenas um óbito.

Nesse panorama, a proporção de óbitos em menores de um ano residentes em Manguinhos, no período de 1996 a 2000, é de 7,6\% do total de mortes de residentes no bairro. A Figura 2 ilustra o comportamento desse índice ao longo dos cinco anos estudados, comparando-o com os dos demais bairros da X RA e o do Município do Rio de Janeiro.

Dentre os selecionados, Manguinhos é o que possui, em toda a série, a maior proporção de óbitos em menores de um ano. A distância só se reduz consideravelmente em 2000, quando o índice decresce do patamar de $10,2 \%$, registrado em 1999 (o maior de todas as séries apresentadas), para 5,7\%, próximo dos 5,3\% que Bonsucesso registrou nesse mesmo ano. É importante destacar que mesmo os maiores índices dos bairros de Ramos (5,5\%, em 1998) e Olaria (3,3\%, em 1996) e do Município do Rio de Janeiro (4,3\%, em 1996 e 1997) não superam o menor índice de Manguinhos.

Relacionando as mortes de crianças menores de um ano com suas condições de vida, Laurenti et al. (1987:117) afirmam que "idealmente...não deveria morrer nenhuma criança menor de 1 ano de idade...", mas admitem que “...tal fato é praticamente inexistente, pois mesmo que se eliminassem todos os fatores ambien- tais, restariam fatores biológicos responsáveis por algumas mortes". Seguindo este raciocínio, informam que áreas ou países de elevado nível de saúde possuíam, já no final da década de 70, uma mortalidade proporcional em menores de um ano girando em torno de 3,0\%.

Adotando-se esse parâmetro, Olaria é, dentre os locais selecionados, o único que, em 2000 , havia atingido patamar inferior a $3,0 \%$. No caso específico de Manguinhos, é altamente necessário que se monitore o comportamento deste indicador, pois, conforme já citado, ele manteve uma trajetória ascendente, que só foi interrompida em 2000. É preciso analisá-lo nos próximos anos, para que se possa constatar se há, realmente, uma tendência de queda e quais seriam seus motivos.

A Figura 3 ilustra o comportamento da taxa de mortalidade infantil (TMI) nos bairros da X RA e no Município do Rio de Janeiro, demonstrando que Manguinhos é o único cujo indicador mantém-se em ascensão no período 1996 a 1999. Neste percurso, ele supera, já em 1997, o Município do Rio de Janeiro (que, em 1996, possuía a maior TMI dentre os selecionados) e atinge, em 1999, o mais alto coeficiente de todos: $32,1 / 1.000$ nascidos vivos.

Todavia, em 2000, Manguinhos registra queda, o que o coloca abaixo do Município do Rio de Janeiro, mas ainda acima de Olaria, Ramos e Bonsucesso, que, nesse ano, não atingem o patamar de 20,0/1.000 nascidos vivos (NV). Outro

Figura 2

Proporção de óbitos em menores de um ano da X Região Administrativa e Município do Rio de Janeiro,

Brasil, 1996 a 2000
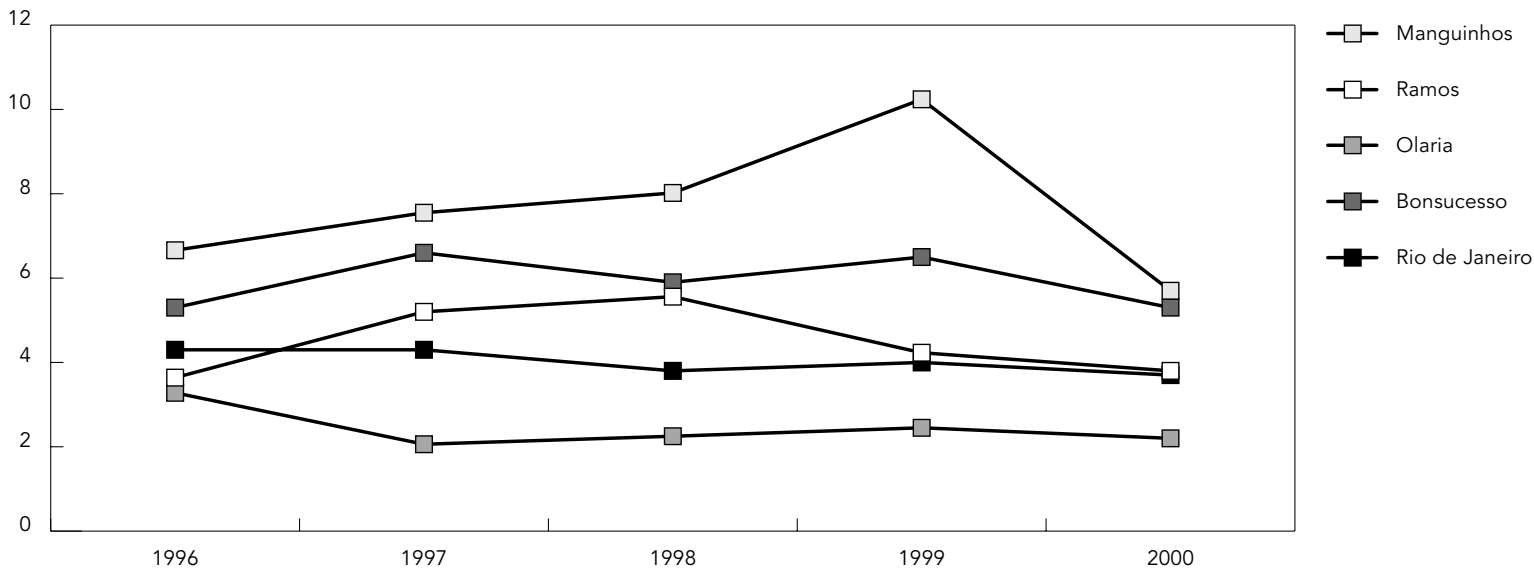
ponto de destaque é que, nos cinco anos investigados, a menor TMI de residentes em Manguinhos (22,3/1.000 NV, em 2000) é superior às taxas registradas em Olaria e igual à maior de Bonsucesso.

Analisando a mortalidade infantil, Laurenti et al. (1987) comentam que os padrões adotados em uma determinada época para aferir se a TMI (e também outras taxas) é baixa, média, alta, ou muito alta, tendem a se tornar obsoletos de acordo com o incremento das condições de vida e de saúde. Assim, explicam que o parâmetro "baixo", que já havia sido referenciado como "inferior a 30 por mil NV", não dava conta da realidade dos países 'desenvolvidos' em fins da década de 80, e que havia sido revisto para "inferior a 20 por mil NV". Além disso, afirmam que "a maioria dos países de alto nível de saúde apresenta um coeficiente de mortalidade infantil próximo, ou inferior, a 15 por mil. Alguns já passaram a barreira dos 10 por mil nascidos vivos" (Laurenti et al., 1987:107). Esta informação é corroborada pela Organização Mundial da Saúde (WHO, 2001), que demonstra que, em 1998, Estados Unidos e Bélgica apresentavam taxas de, respectivamente, sete e oito por mil nascidos vivos.

Cotejando-se esses dados com os dos bairros da X RA e do Município do Rio de Janeiro, constata-se que somente Manguinhos e Rio de Janeiro estão acima da TMI de 20,0/1.000 NV, e que Olaria é o único que se aproxima do pata- mar de 15,0/1.000 NV. Deve-se ter extrema atenção com os índices de Manguinhos, monitorando-se as TMIs para os próximos anos, pois esta taxa é crescente no período de 1996 a 1999, quando superou, inclusive, a taxa de 30,0/1.000 NV.

A Figura 4 apresenta as taxas de mortalidade neonatal ou infantil precoce (crianças falecidas durante os primeiros 28 dias de vida) e de mortalidade pós-neonatal ou infantil tardia (crianças falecidas entre o 29o dia de vida e um ano de idade) de residentes em Manguinhos. Sua interpretação aponta tendências divergentes: no período 1996-1999, no qual a TMI esteve em contínua ascendência, a predominância alterna-se, uma vez que, no biênio 1996/1997, a mortalidade pós-neonatal foi a predominante e, no biênio 1998/1999, a mortalidade neonatal assumiu a supremacia. Nota-se, no entanto, que, mesmo nos anos em que não representava a principal, a taxa de mortalidade neonatal registrou crescimento, enquanto a pósneonatal decai em 1998 para, em 1999, novamente crescer.

Já em 2000, a TMI de Manguinhos decresce, fortemente influenciada pela queda da mortalidade neonatal, que atinge o menor coeficiente dos cinco anos estudados, num processo que, se for mantido nos anos seguintes, afastase do padrão referido por Laurenti et al. (1987: 118): "À medida que as condições ambientais vão permitindo reduzir a mortalidade infantil (melhor saneamento, melhor nutrição, vacina-

Taxa de mortalidade infantil para os bairros da X Região Administrativa e Município do Rio de Janeiro, Brasil, 1996 a 2000 .

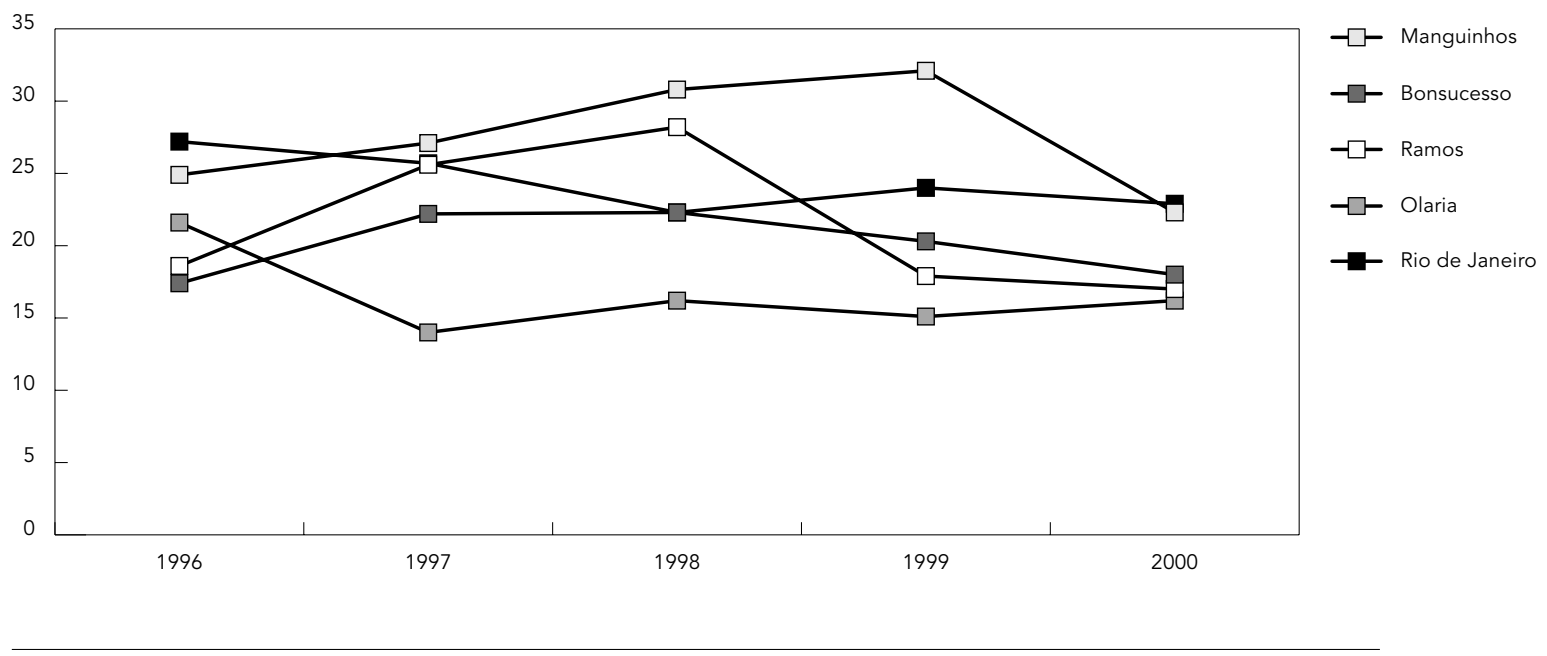


Figura 4

Taxa (/1.000 nascidos vivos) de mortalidade neonatal e pós-neonatal em residentes em Manguinhos, Rio de Janeiro, Brasil, 1996 a 2000

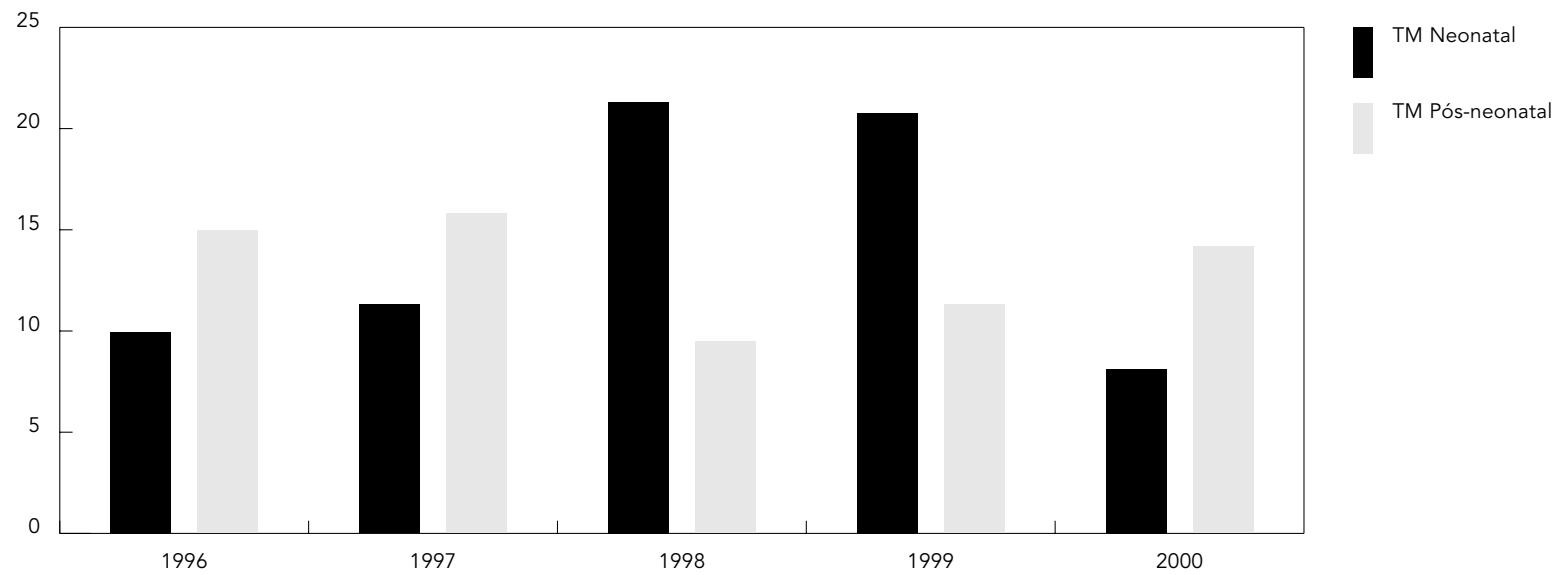

ção, etc.), verifica-se que essa redução (da TMI) se faz às custas da infantil tardia. Posteriormente, consegue-se reduzir a neonatal, atuando em condições pré-natais, assistência ao parto e pósnatal imediato".

Um dado instigante é que, nos anos de 1996 a 2000, não houve nenhuma morte materna de residentes em Manguinhos. Faz-se necessário que a SMS-RJ, por meio do comitê de mortalidade materna, analise de forma mais detida esta situação a fim de verificar se ela é um indicador da qualidade de assistência pré-natal ou se ela está subnotificada, pois, conforme afirma Laurenti (1995:309), “... as chamadas causas maternas... são as mais mal notificadas... mesmo em áreas com excelente cobertura de registro civil, como é o caso, por exemplo, de várias capitais do Brasil - e nas quais pode-se dizer que todas as mortes são registradas - as mortes maternas são, quase sempre, subinformadas... Um trabalho clássico, realizado pela Organização Pan-Americana da Saúde,... mostrou que as taxas de mortalidade por esse grupo de causa eram, na realidade, bem maiores do que expressavam as estatísticas oficiais, chegando, em algumas cidades latino-americanas, a ser de 50,0\% a 60,0\% mais altas".

Analisando-se as principais causas de mortalidade de crianças e adolescentes em Manguinhos, constata-se que as causas externas e as afecções perinatais são responsáveis por 59,3\% do total de óbitos ocorridos no período 1996 a 2000. As primeiras constituem-se nas que mais mataram nos anos de 1996 (42,8\%), 1997 (28,6\%) e 2000 (40,0\%), enquanto as segundas assumiram esta posição em 1999 (50,0\%). Além disso, em 1998, ambas apresentaram a mesma porcentagem de óbitos $(29,2 \%)$.

A comparação dessas proporções com as dos demais bairros da X RA informa que, em Ramos, Olaria e Bonsucesso, as causas externas e as afecções perinatais também são as principais causas de óbito de crianças e adolescentes. Entretanto, enquanto nos dois primeiros bairros a proporção dos cinco anos investigados é superior à de Manguinhos $(62,7 \%$ e $63,2 \%$, respectivamente), no terceiro ela é inferior (56,6\%).

Ainda sobre essa questão, Bonsucesso é o único desses bairros no qual as causas externas foram majoritárias em três anos $(32,6 \%$, em 1996; 25,4\%, em 1998; e 34,5\%, em 2000). Em Ramos, as afecções perinatais só são superadas pelas causas externas em 1997 (30,7\%) e, em Olaria, somente em 1998 há um nivelamento de ambas, que atingem, cada uma, 35,7\%.

A Tabela 1 apresenta a principal causa de morte em crianças e adolescentes residentes em Manguinhos, distribuída de acordo com o ano de ocorrência e com faixas etárias selecionadas.

Aprofundando-se as informações nela contidas, constrói-se o seguinte panorama:

Dos 63 casos de crianças menores de um ano que, de 1996 a 2000, morreram em Manguinhos, 33 (52,4\%) foram devidos às afecções 
Principal causa de morte de crianças e adolescentes por faixas etárias selecionadas, residentes em Manguinhos, Rio de Janeiro, Brasil, 1996 a 2000.

\begin{tabular}{|c|c|c|c|c|c|c|}
\hline & $<1$ ano & 1 a 4 anos & 5 a 9 anos & 10 a 14 anos & 15 a 18 anos & Total \\
\hline 1996 & $\begin{array}{l}\text { Afecções perinatais } \\
(4-40,0 \%)\end{array}$ & $\begin{array}{l}\text { Neoplasia, } \\
\text { indeterminadas } \\
\text { e causas externas } \\
\text { ( } 1 \text { cada }-50,0 \% \text { cada) }\end{array}$ & $\begin{array}{l}\text { Causas externas } \\
(2-100 \%)\end{array}$ & $\begin{array}{l}\text { Neoplasia } \\
(1-100 \%)\end{array}$ & $\begin{array}{l}\text { Causas externas } \\
(5-100 \%)\end{array}$ & $\begin{array}{l}\text { Causas externas } \\
(9-42,9 \%)\end{array}$ \\
\hline 1997 & $\begin{array}{l}\text { Afecções perinatais } \\
(5-41,7 \%)\end{array}$ & $\begin{array}{l}\text { Causa externa } \\
(1-100 \%)\end{array}$ & $\begin{array}{l}\text { Doenças do sangue } \\
\text { e doenças do } \\
\text { aparelho respiratório } \\
\text { ( } 1 \text { cada }-50,0 \% \text { cada) }\end{array}$ & $\begin{array}{l}\text { Causas externas } \\
(2-66,7 \%)\end{array}$ & $\begin{array}{l}\text { Causas externas } \\
(3-100 \%)\end{array}$ & $\begin{array}{l}\text { Causas externas } \\
(11-52,4 \%)\end{array}$ \\
\hline 1998 & $\begin{array}{l}\text { Afecções perinatais } \\
(7-53,8 \%)\end{array}$ & $\begin{array}{l}\text { Doenças do aparelho } \\
\text { respiratório } \\
(1-100 \%)\end{array}$ & $\begin{array}{l}\text { Causas externas e } \\
\text { doenças infecto- } \\
\text { parasitárias } \\
\text { ( } 1 \text { cada }-50,0 \% \text { cada) }\end{array}$ & $\begin{array}{l}\text { Causas externas e } \\
\text { doenças do aparelho } \\
\text { respiratório } \\
\text { ( } 1 \text { cada }-50,0 \% \text { cada) }\end{array}$ & $\begin{array}{l}\text { Causas externas } \\
(5-83,3 \%)\end{array}$ & $\begin{array}{l}\text { Causas externas e } \\
\text { afecções perinatais } \\
\text { ( } 7 \text { cada }-31,8 \% \text { cada) }\end{array}$ \\
\hline 1999 & $\begin{array}{l}\text { Afecções perinatais } \\
(11-64,7 \%)\end{array}$ & $\begin{array}{l}\text { Doenças do sangue } \\
(1-100 \%)\end{array}$ & Não houve óbito & $\begin{array}{l}\text { Causas externas } \\
(1-100 \%)\end{array}$ & $\begin{array}{l}\text { Causas externas } \\
(2-66,7 \%)\end{array}$ & $\begin{array}{l}\text { Afecções perinatais } \\
(11-57,9 \%)\end{array}$ \\
\hline 2000 & $\begin{array}{l}\text { Afecções perinatais } \\
(6-54,5 \%)\end{array}$ & $\begin{array}{l}\text { Doenças do aparelho } \\
\text { respiratório. } \\
(3-75,0 \%)\end{array}$ & $\begin{array}{l}\text { Neoplasia } \\
(1-100 \%)\end{array}$ & $\begin{array}{l}\text { Causas externas } \\
(2-50,0 \% 0)\end{array}$ & $\begin{array}{l}\text { Causas externas } \\
(9-90,0 \%)\end{array}$ & $\begin{array}{l}\text { Causas externas } \\
(12-40,0 \%)\end{array}$ \\
\hline
\end{tabular}

perinatais, cujos principais grupos de causa foram a síndrome da angústia respiratória do recém-nascido (nove), a ruptura prematura das membranas (cinco) e a septicemia bacteriana não especificada (cinco). Outras causas de morte importantes nesta faixa etária foram as doenças infecciosas e parasitárias $(14,3 \%)$, as doenças do aparelho respiratório $(9,5 \%)$ e as másformações congênitas $(6,3 \%)$.

$\mathrm{Na}$ faixa etária de um a quatro anos, houve, no período estudado, dez mortes, das quais quatro $(40,0 \%)$ por doenças do aparelho respiratório, três $(30,0 \%)$ por causas externas, uma por neoplasia, uma por doença do sangue e outra por causas mal-definidas e desconhecidas de mortalidade.

A faixa etária de um a cinco anos é a que possui, em Manguinhos e para o período investigado, o menor número absoluto de óbitos, sete, dos quais três $(42,9 \%)$ por causas externas, um por doença do aparelho respiratório, uma por doença infecciosa e parasitária, uma por neoplasia e uma por doença do sangue e transtorno imunitário.

O número absoluto de óbitos em Manguinhos tende a crescer com a aproximação da adolescência. A faixa etária de 10 a 14 anos registra, de 1996 a 2000, 11 óbitos, dos quais seis $(54,1 \%)$ por causas externas, dois por doenças do aparelho respiratório, um por neoplasia, um por doenças do sistema nervoso e um por causa desconhecida.

Esse crescimento torna-se nítido ao enfocar-se a faixa etária de 15 a 18 anos, que, de 1996 a 2000, registrou 27 óbitos, cuja imensa maioria - 24 , o que equivale a $88,9 \%$ do total deve-se às causas externas.

Está claro que o crescimento do número absoluto de mortes nas faixas etárias que englobam adolescentes é devido ao crescimento das mortes por causas externas. Contudo, é extremamente importante conhecer quais causas externas predominam em cada faixa etária.

Tomando-se como ponto de partida a faixa etária de 5 a 9 anos que, apesar de não englobar adolescentes, é a primeira na qual as causas externas são majoritárias, observa-se que as três mortes por essas causas ocorreram devido a acidentes de trânsito, afogamento e exposição à fumaça.

Na faixa etária seguinte, a de 10 a 14 anos, a situação modifica-se: das seis mortes por causas externas ocorridas de 1996 a 2000, três foram por acidentes de transporte; uma por agressão; uma por evento de intenção indeterminada; e uma por disparo de arma de fogo, o que demonstra que, nesta faixa, já há pessoas morrendo em virtude de homicídios.

Esse panorama consolida-se completamente na faixa etária de 14 a 18 anos: das 24 mortes 
por causas externas registradas nos cinco anos estudados, uma foi por contato com objeto contundente, intenção não determinada; uma por fato ou evento especificado, intenção não determinada; uma por fato ou evento não determinado, intenção não determinada; duas por acidentes de transporte; quatro por agressões por outros meios; e 15 por disparo de arma de fogo; o que significa que $79,2 \%$ dos adolescentes desta faixa etária foram assassinados.

\section{Relacionando a mortalidade às condições de vida: conclusões sobre Manguinhos}

A proposta de estabelecer, na pesquisa social e mais especificamente no campo da saúde pública, uma efetiva interação das dimensões quantitativas e qualitativas das realidades estudadas, apesar de não ser propriamente inovadora, representa, ainda hoje, um importante desafio a ser enfrentado pelos profissionais dessas áreas.

Logicamente, os problemas e dificuldades envolvidos na consecução dessas iniciativas são bastante complexos, perpassando vários e diferentes aspectos, dentre os quais se ressaltam desde as divergências em torno de concepções teórico-metodológicas até a rarefação de recursos para a formação e manutenção de equipes interdisciplinares.

Assim, faz-se necessário mencionar os problemas e dificuldades enfrentados pelos autores deste artigo, pois, apesar de tradicionais e já amplamente debatidos pelos pesquisadores da área, continuam a intervir nos rumos e resultados de estudos, sobretudo no que se refere à inexistência de dados sobre a distribuição por idade da população do município e de seus bairros (quantas pessoas têm um ano, dois, três...); à ordem de grandeza do número absoluto de mortes de residentes em Manguinhos que, por ser reduzida (o que não significa que as mortes possam ser consideradas como reduzidas), transforma poucos eventos em elevadas porcentagens e taxas e à confiabilidade de determinadas informações dos Registros de Óbitos, tais como as relatadas por Drummond Jr. et al. (1989), Abreu \& Rodrigues (2000) e Simões \& Reichenhein (2001).

Nesse contexto, há que se proceder a um esclarecimento no que diz respeito à X-Ramos. Até 1997, os complexos do Alemão e da Maré não eram considerados como bairros, mas como territórios pertencentes aos bairros da XRamos (SMS, 1999a). Após aquele ano, eles não só foram desmembrados, como passaram a fazer parte de RAs específicas (XXIX e XXX, res- pectivamente). Assim, a população de Bonsucesso, Ramos, Manguinhos e, conseqüentemente, da X-Ramos, foi consideravelmente reduzida, o que explica as discrepâncias entre os dados de população aqui apresentados e os de trabalhos como o de Amorim (1995), que, em 1995, registrava um número muito maior de habitantes do que aquele que apresentamos para o ano 2000.

Todavia, tal emancipação parece também criar certas dificuldades, pois, se é plenamente possível identificar a população das RAs e dos bairros, torna-se mais difícil fazê-lo no que concerne aos óbitos. Uma comparação do número de óbitos demonstra que Alemão e Maré, locais tradicionalmente marcados pelas parcas condições de vida, pela delinqüência, e pelo tráfico de drogas, possuem número absoluto de óbitos e taxas de mortalidade bastante reduzidos, enquanto Bonsucesso registra níveis bastante superiores aos dos demais bairros do município. Isto leva a crer que pode estar havendo uma superestimação de óbitos nesse bairro e uma subestimação nos dois complexos, fato que precisa ser apurado pela SMS-RJ.

Situadas as principais questões problemáticas, prossigamos com a proposta de articulação e compreensão das relações entre a mortalidade e as condições de vida, partindo dos dados de mortalidade infantil de residentes em Manguinhos.

De acordo com Carvalho (1993:51): “A análise dos óbitos infantis nos permite, mais do que em qualquer outro grupo, fazer correlações diretas com as condições de vida de uma dada localidade, pelo impacto com que as alterações no padrão socioeconômico ou no acesso aos serviços de saúde interferem nos coeficientes de mortalidade".

Conforme apresentado no tópico anterior, Manguinhos possui a maior proporção de óbitos em menores de um ano (superando, inclusive, o Município do Rio de Janeiro) e a maior taxa de mortalidade infantil dos bairros da XRamos. Analisando-se essas mortes, constatase que a grande maioria decorre de causas evitáveis, o que indica, dentre outros, problemas no acesso aos serviços de saúde.

De fato, a única unidade pública de saúde localizada em Manguinhos é o CSEGSF/FIOCRUZ (portanto, federal), à qual, desde 2000, vincula-se o PSF de Manguinhos. De acordo com a SMS-RJ (1999b), a X-Ramos conta com um Centro Municipal de Saúde (CMS) e um Posto de Atendimento Médico (PAM), ambos no bairro de Ramos, e o Hospital Geral de Bonsucesso. Levando-se em conta a AP 3.1 (na qual se insere a X-Ramos), a Secretaria lista dois CMSs (Pe- 
nha e Ilha do Governador), três PAMs (dois na Ilha do Governador e um na Penha), quatro postos de saúde (dois na favela da Maré, um em Vigário Geral e um em Jardim América), uma unidade de atendimento primário (Cordovil), um instituto de pediatria (Ilha do Governador) e três hospitais (dois na Ilha do Governador e um na Penha).

Fique claro que não é objetivo deste artigo discutir se essa rede está, ou não, organizada de acordo com parâmetros oficiais ou reconhecidos pelas organizações de saúde. Seu intuito é demonstrar que os cidadãos residentes em Manguinhos têm sérias dificuldades em acessálas, conforme explicam as profissionais do PSF:

"Como essa comunidade é um pouco distante (nota: Mandela de Pedra, uma das doze que formam Manguinhos), até o PSF entrar, 80,0\% das pessoas não acessavam uma unidade de saúde... tinha o fator dinheiro da passagem para ir para outros lugares. Eles simplesmente não iam porque não tinham dinheiro da passagem e não vinham aqui (nota: no CSEGSF) porque não tinham comprovante de residência".

“... eles vão muito no Hospital Geral de Bonsucesso, na emergência. Isso é, eles vão quando a criança já está com uma infecção respiratória grave... e eles vão muito no Paulino Werneck na Ilha... porque sempre há um pediatra. Tinha a queixa que em Bonsucesso nunca tinha Pediatra".

“... a questão do parto: nós não temos aqui na região da AP 3.1 leitos obstétricos suficientes. Isso é problemático. Ultra-sonografia não existe. A rede, enquanto AP 3.1, não oferece esse tipo de exame. Precisa referenciar para outra AP ou as gestantes têm que ter condições de estar fazendo esse exame".

“... quando não tem o serviço aqui no Centro de Saúde nós estamos encaminhando. Temos tido contato com os PAMs da Ilha do Governador... o 634 (nota: linha de ônibus) deixa as pessoas em frente, mas nem sempre as pessoas têm dinheiro para estar pagandoa passagem...elas não têm dinheiro para pagar passagem e aí se desmotivam. Não têm continuidade no tratamento, não têm acompanhamento. É uma questão de acesso geográfico mesmo... o Diretor do Centro de Saúde estava com uma proposta muito interessante de estar colocando algumas especialidades aqui dentro... seria superinteressante porque reverteria essa questão que a gente está vivendo agora... facilitando o acesso das pessoas e aumentando a capacidade de recursos humanos... seria um dos passos para estar revertendo os problemas".

Outro ponto bastante preocupante é que, dos nove óbitos por doenças infecciosas e pa- rasitárias (DIPs) ocorridos em crianças menores de um ano residentes em Manguinhos, quatro deveram-se ao grupo de causas diarréicas, fato que possui extrema vinculação com as condições de saneamento, esgoto e abastecimento de água. Esta relação é explicitada nos Diagnósticos Rápidos Participativos (DRPs) realizados pela Fundação Bento Rubião (2000) para o DLIS Manguinhos, que informam que todas as comunidades que compõem o bairro possuem sérios problemas de esgotamento e saneamento, variando da inexistência à obsolescência.

Os depoimentos das profissionais do PSF de Manguinhos que trabalham na comunidade de João Goulart ilustram esta situação:

“...Com relação ao esgoto... encontramos bastante problema devido a uma obra mal feita... quando chove, esse esgoto enche muito, causando doenças, principalmente em crianças... diarréias e problemas de pele".

“... João Goulart (nota: outra comunidade de Manguinhos), inicialmente, tinha infra-estrutura. Depois houve um crescimento em demasia e desordenado, que desorganizou essa infra-estrutura. Choveu, transborda tudo! Até porque lá era um charco que foi aterrado e fica abaixo do nível do rio. Quando enche, a água do rio volta e entra na comunidade".

Note-se que essa situação ocorre em uma comunidade na qual as condições de vida não são consideradas "muito ruins". Das comunidades de Manguinhos, Mandela de Pedra é a que possui as piores condições de vida, conforme explicam as profissionais do PSF que lá trabalham:

"Mandela é uma invasão. É tudo barraco... um pedaço de lá é um retão onde as casas ficam à beira do Rio do Cunha. É um dos piores que tem. As cozinhas $e$ os banheiros ficam sobre aquela lama do rio. Uns têm banheiro, outros não. Uns têm vaso, outros não. É um buraco no chão para fazer as necessidades...".

“...o esgoto é a céu aberto mesmo... há casas que têm esgoto dentro da própria casa. Manilhas semi-abertas...".

“...rato é algo que tem demais! Inclusive nós tivemos uma criança essa semana que foi abrir um tampão e o rato veio, pegou o biscoito da mão dela e deu uma dentada na mão dela. Tem mães que falam que não dormem porque ficam espantando os ratos do berço das crianças...".

“...as crianças lá têm muita diarréia... muita verminose. Botam muito verme pelo nariz, muito mesmo! A gente orienta sobre a água. A gente insiste para as pessoas comprarem um filtro e ferver a água, mas muitas reclamam que ferver gasta gás e eles não têm dinheiro para comprar". 
“...um homem falou comigo que coava a água num coador de pano porque havia muito resíduo... a gente está fazendo um levantamento de água, coletando em alguns pontos".

Terceiro grupo que mais causa óbitos infantis em Manguinhos, as doenças do aparelho respiratório vitimaram, de 1996 a 2000, seis crianças menores de um ano que lá residiam. As profissionais de saúde da família também identificaram esta questão:

"Nós temos muito problema respiratório... devido à refinaria de Manguinhos e ao bairro ser uma área muito poluída... as crianças têm muitas IRAs, que são as infecções respiratórias agudas... porque o índice de poluição é muito alto".

"Tem dia que a gente passa mal lá!"

No que diz respeito aos adolescentes, os dados do SIM demonstram que, de 1996 a 2000, as causas externas foram as que mais mataram os residentes em Manguinhos e que, a partir do 14 anos de idade, a mais recorrente é, de longe, o homicídio.

Em seu estudo sobre o envolvimento de jovens com o tráfico de drogas no Município do Rio de Janeiro, Cruz Neto et al. (2001) demonstram como, ao longo do século XX, o número de homicídios de adolescentes cariocas aumenta à medida que cresce o número de adolescentes presos e apreendidos por participarem do tráfico de drogas, processo que se intensifica a partir dos anos 80 e atinge seu auge na segunda metade da década de 90 .

Infelizmente, essa perigosa relação adolescentes/tráfico de drogas/homicídios também ocorre em Manguinhos:

"Qual o principal problema de saúde dos adolescentes? ...nos meninos é o envolvimento com drogas... tanto uso quanto tráfico... eles se envolvem muito cedo. Largam, param de estudar, se envolvem naquilo".

“...como as portas de emprego estão fechadas, eles vão para o tráfico... o tráfico impera totalmente".

“...quando tem batida da polícia ou troca de tiro, as mães ficam loucas".
"Já tive vezes de fazer visita domiciliar e um adolescente de 15 anos estar espancado porque correu da polícia, caiu de laje, fraturou costela, mas também tinha medo de procurar a emergência. Ficou se tratando em casa".

“...tem um que eu conheço... uma vez, conversando comigo, ele falou assim: Ah, minha vida agora é matar ou morrer. Eu sei que não tenho muito futuro, não".

A relação entre óbitos de adolescentes por causas externas e sexo demonstra que estas causas atingem, predominantemente, o sexo masculino: 5:1 (1997), 6:1 (1998) e 10:1(2000). Tal relação não pôde ser calculada em 1996 e 1999, já que, para estes anos, não se registrou nenhuma morte no sexo feminino.

O perfil do adolescente morto em Manguinhos coincide com o perfil nacional traçado pelo CLAVES (1991:12): “...pobre, sexo masculino, idade média 15-18 anos, residente nas periferias ou favelas urbanas, assassinado, geralmente por projétil de arma de fogo e denominado 'marginal', nos registros policiais".

Por tudo que aqui foi apresentado, compreende-se que a grande maioria dos óbitos de crianças e adolescentes residentes em Manguinhos ocorreu por causas plenamente evitáveis. Pior: tais mortes carregam consigo uma triste nódoa da sociedade carioca - e, por extensão, da brasileira -, que é o fato de terem ocorrido, nas proporções e situações descritas, em seres humanos cujas precárias condições de vida foram fundamentais para abreviar sua existência.

A conclusão a que se chega, embora um tanto desgastada por desventuras políticas, é que esse quadro pode ser revertido, desde que seus componentes sociais sejam encarados como prioridades pelo Estado e sejam objetos de um conjunto coerente e articulado de políticas públicas. Para isso, o poder público deve ser pressionado diretamente pela sociedade civil organizada e pela articulação desta com instituições como o Conselho Tutelar e o Ministério Público, que devem ser mobilizadas e sensibilizadas a respaldar as iniciativas de promoção, desenvolvimento local e melhoria das condições de vida da população. 


\section{Referências}

ABREU, D. M. X. \& RODRIGUES, R. N., 2000. Diferenciais de mortalidade entre as regiões metropolitanas de Belo Horizonte e Salvador, 1985-1995. Revista de Saúde Pública, 34:514-521.

ALMEIDA, A. C., 1997. A Qualidade de Vida no Estado do Rio de Janeiro. Niterói: EdUFF

AMORIM, J. W. (org.), 1995. Indicadores de Saúde: Ilha do Governador e Leopoldina. Rio de Janeiro: Fundação Oswaldo Cruz.

BRASIL, 1990. Estatuto da Criança e do Adolescente. Brasília: Ministério da Saúde.

CARVALHO, M. S. (org.), 1993. Análise das Condições de Vida e Morte em Populações Urbanas: Uma Proposta para os Serviços de Saúde. Rio de Janeiro: Escola Nacional de Saúde Pública, Fundação Oswaldo Cruz.

CLAVES (Centro Latino-Americano de Estudos Sobre Violência e Saúde - Jorge Carelli), 1991. Levantamento sobre Extermínio de Crianças e Adolescentes no Brasil. Relatório Técnico. Rio de Janeiro: Escola Nacional de Saúde Pública, Fundação Oswaldo Cruz.

CRUZ NETO, O.; MOREIRA, M. R. \& SUCENA, L. F. M., (no prelo). Nem Soldados nem Inocentes: Juventude e Tráfico de Drogas no Rio de Janeiro. Rio de Janeiro: Editora Fiocruz.

DRUMMOND Jr., M.; LIRA, M. M. T. A.; FREITAS, M.; NITRINI, T. M. V. \& SHIBAO, K., 1989. Avaliação da qualidade das informações de mortalidade por acidentes não especificados e eventos com intenção indeterminada. Revista de Saúde Pública, 33: 273-280.

FCDDHBR (Fundação Centro de Defesa dos Direitos Humanos Bento Rubião), 2000. Diagnóstico Rápido Participativo das Comunidades de Parque Oswaldo Cruz, Nelson Mandela, Mandela de Pedra, Parque João Goulart, CHP2, Comunidade Agrícola Higienópolis, Vila São Pedro, Vila União, Vila Turismo, Parque Carlos Chagas, Conjunto Samora Machel. Relatório Técnico. Rio de Janeiro: FCDDHBR.
LAURENTI, R., 1995. O perfil da mortalidade materna. In: Os Muitos Brasis. Saúde e População na Década de 80 (M. C. S. Minayo, org.), pp. 304-319, Rio de Janeiro: Editora Hucitec.

LAURENTI, R.; MELLO-JORGE, M. H. P. \& LEBRÃO M. L. \& GOTLIEB, S. L. D., 1987. Estatísticas de Saúde São Paulo: E.P.U.

MINAYO, M. C. S., 1990. A violência na adolescência: Um problema de saúde pública. Cadernos de Saúde Pública, 6:278-292

MOREIRA, M. R.; CRUZ NETO, O. \& SUCENA, L. F. M., 2001. Estudo sobre as Condições de vida e Atendimento a Crianças e Adolescentes do Rio de Janeiro - X RA - Ramos. Rio de Janeiro: Departamento de Ciências Sociais, Escola Nacional de Saúde Pública, Fundação Oswaldo Cruz. (mimeo.)

OLIVEIRA, L. A. P. \& MENDES, M. M. S., 1995. Mortalidade infantil no Brasil - Uma avaliação de tendências recentes. In: Os Muitos Brasis. Saúde e População na Década de 80 (M. C. S. Minayo, org.), pp. 291-303, Rio de Janeiro: Editora Hucitec.

SIMÕES, E. M. S. \& REICHENHEIM, M. E., 2001. Confiabilidade das informações de causa básica nas declarações de óbito por causas externas em menores de 18 anos no Município de Duque de Caxias, Rio de Janeiro, Brasil. Cadernos de Saúde Pública, 17:521-531.

SMS-RJ (Secretaria Municipal de Saúde do Rio de Janeiro), 1999a. Guia de Saúde da Cidade do Rio de Janeiro. Rio de Janeiro: Imprensa da Cidade.

SMS-RJ (Secretaria Municipal de Saúde do Rio de Janeiro), 1999b. Mortalidade por Causas Externas no Município do Rio de Janeiro, 1998. 10 Julho $2001<$ http://www.saude.rio.rj.gov.br>.

SMS-RJ (Secretaria Municipal de Saúde do Rio de Janeiro), 2001. Banco de Dados - Sistema de Informação de Mortalidade. Rio de Janeiro: SMS-RJ.

WHO (World Health Organizacion), 2001. Basic Health Indicators from the World Health Report. July 2001 <http://www.nt.who.int/whosis/statistics/ menu.cfn.>.

Recebido em 7 de dezembro de 2001

Versão final reapresentada em 8 de maio de 2002

Aprovado em 30 de julho de 2002 